\title{
Kinetic and Thermodynamic Studies of Chromium (VI) Sorption by Pure and Carbonized Fluted Pumpkin waste biomass (Telfairia occidentalis Hook F.)
}

\author{
Timi Tarawou ${ }^{* 1}$ and Michael Horsfall $\mathbf{J r}^{1}$ \\ ${ }^{1}$ Department of Pure and Industrial Chemistry, University of Port Harcourt, P. M. B. 5323, Port \\ Harcourt, Nigeria.E-mail: ttarawoufgc@yahoo.com
}

\begin{abstract}
The adsorption of chromium (VI) ions from aqueous solution was studied using pure and carbonized fluted pumpkin waste biomass (FPWB). The kinetic data shows a pseudo-first-order mechanism with rate constants of $1.26 \times 10^{-2}$ and $1.933 \times 10^{-2} \mathrm{mg} \mathrm{g}^{-1} \mathrm{~min}^{-1}$ for the pure and carbonized FPWB, respectively. While the pseudo-second-order mechanism has rate constants of $0.93 \times 10^{-1}$ and $1.33 \times 10^{-1} \mathrm{mg} \mathrm{g}^{-1} \mathrm{~min}^{-1}$ for the pure and carbonized waste biomass respectively. The pseudo-second order kinetic model was found to be more suitable for describing the experimental data based on the correlation coefficient values $\left(R^{2}\right)$ of 0.9975 and 0.9994 obtained for pure waste biomass (PWB) and carbonized waste biomass (CWB), respectively. The results obtained from this study show that $P W B$ and $C W B$ have very high removal capacity for chromium (VI) from aqueous solution over a range of reaction conditions. Thus, fluted pumpkin waste biomass (Telfairia occidentalis Hook F) is a potential sorbent for the treatment of industrial effluents containing chromium (VI) contaminant.
\end{abstract}

Keywords: Kinetic, thermodynamic, chromium (VI), sorption, fluted pumpkin waste biomass.

\section{Introduction}

The element chromium belongs to the $6^{\text {th }}$ group in the latest IUPAC periodic table and exists in the aqueous environment mainly in +III and +VI states. $\mathrm{Cr}$ (III) is non-toxic, and an essential species to mammals that helps the body to control blood-sugar levels in trace concentrations, but toxic to fish when present in water above $5.0 \mathrm{mg} / \mathrm{l}^{1} . \mathrm{Cr}$ (VI) is a powerful epithelial irritant, and a confirmed human carcinogen ${ }^{2}$. Furthermore, $\mathrm{Cr}$ (VI) is toxic to many plants, aquatic animals and bacteria ${ }^{3}$. Water containing $\mathrm{Cr}(\mathrm{VI})$ above $0.05 \mathrm{mg} / \mathrm{l}$ is toxic to both mammals and aquatic organisms ${ }^{4}$. Most industries like paint and pigment manufacturing, leather tanning, chrome plating, textile, match, etc in underdeveloped countries discharge wastewater into surface water containing $\mathrm{Cr}(\mathrm{VI})$ after reduction to the trivalent state. The major drawback of this conventional treatment method is the high cost of chemicals used for the reduction process and incomplete reduction of $\mathrm{Cr}(\mathrm{VI})$, which may produce toxic sludge due to surface adsorption of $\mathrm{Cr}$ (VI) onto the $\mathrm{Cr}$ (III) hydroxide precipitate. It is therefore necessary to explore viable technologies for controlling the concentration of $\mathrm{Cr}$ (VI) in aqueous discharges.

\section{* Corresponding author}


Surface adsorption is found to be an important method for the treatment of toxic elementcontaminated water. Several adsorbents such as clay ${ }^{5}$, used tyres and sawdust ${ }^{6}$, hydrotalcite ${ }^{7}$, activated carbon $^{8}$, cassava waste biomass ${ }^{9}$, caladium bicolor (wild cocoyam) ${ }^{10}$, water hyacinth biomass ${ }^{11}$, hydrous titanium oxide ${ }^{12}$, ion-exchange $\operatorname{resin}^{13}$, etc have been reported. The fluted pumpkin waste biomass has earlier been evaluated ${ }^{14}$, for its surface characteristics and found to posses great potentials as adsorbent for divalent metals; $\mathrm{Pb}^{2+}, \mathrm{Cd}^{2+}$ and $\mathrm{Zn}^{2+}$. The sorption mechanism was observed to be an ion-exchange type process. This success has motivated us to try this adsorbent for other metal ions such as $\mathrm{Cr}$ (VI) in aqueous solution. The purpose of this study is to determine the effect of contact time and temperature on the removal of $\mathrm{Cr}$ (VI) from aqueous solution using pure waste biomass (PWB) and carbonized waste biomass (CWB) of the fluted pumpkin. The time dependent data of this study is analyzed to determine the suitability of the pseudo-first and pseudo-second order kinetic models for the sorption process. An evaluation of thermodynamic parameters on Cr (VI) sorption onto PWB and CWB is also made.

\section{Experimental Methods}

The fluted pumpkin waste biomass (FPWB) was collected from Choba market in Obio/Akpor Local Government Area of Rivers State of Nigeria. Samples collected were washed with water to remove sand, cut into smaller pieces and air dried for two days in the Laboratory. The air dried biomass was dried in an oven at $50^{\circ} \mathrm{C}$, after which it was pulverized using a grinder (Lander Cisa 2D). The ground biomass was divided into two portions. The first portion was left as pure waste biomass (PWB) while the second portion was carbonized to form the carbonized waste biomass (CWB).

\section{Carbonization}

Carbonization was carried out in the Plant Physiology and Anatomy Laboratory of the University of Port Harcourt, Nigeria using a muffle furnace (Carbolite Sheffield England, LMF 4) which allowed limited supply of air. The biomass was carbonized at $450^{\circ} \mathrm{C}$ for three hours after which the charred product was allowed to cool to room temperature in 24 hours. It was then transferred to a desiccator to prevent entry of moisture and dirt. The carbonized waste biomass (CWB) was then sieved through a $106 \mu \mathrm{m}$ mesh tyler sieve. This provided a fine and uniform particle size of the carbonized biomass that was used as adsorbent in this study.

\section{Activation of the pure biomass}

The pure biomass was transferred into a $2000 \mathrm{ml}$ volumetric flask containing $1000 \mathrm{ml}$ of $0.1 \mathrm{M} \mathrm{HCl}$ and left to stand for 24 hours. The mixture was then filtered and the residue washed with distilled water several times until its $\mathrm{pH}$ was 7 (neutral). The washed pure biomass was then air-dried, pulverized and sieved through a $106 \mu \mathrm{m}$ mesh tyler sieve to obtain a fine and uniform particle size of the pure waste biomass (PWB).

\section{Preparation of stock solution}

A stock solution of chromium (VI) with a concentration of $1000 \mathrm{mg} / \mathrm{l}$ was prepared by dissolving $4.66 \mathrm{~g}$ of $\mathrm{K}_{2} \mathrm{Cr}_{2} \mathrm{O}_{7}$ in $1000 \mathrm{ml}$ of distilled water. The working solution was prepared by diluting the stock solution with distilled water to give the appropriate concentration of the working solutions. 


\section{Determination of the effect of contact time}

$1.0 \mathrm{~g}$ each of the PWB and CWB of $106 \mu \mathrm{m}$ mesh particle size were weighed and placed in five different plastic bottles with cover. $50 \mathrm{ml}$ of Chromium (VI) solution of concentration 100 $\mathrm{mg} / \mathrm{l}$ was prepared from the stock solution and added to the PWB and CWB in different plastic bottles with time labels of 5, 10, 30, 60 and 90 minutes respectively. The mixtures were adjusted to $\mathrm{pH}$ of 5.0. The plastic bottles containing the mixtures were clamped to a mechanical shaker and agitated to the appropriate time interval. At the end of agitation time, the mixtures were allowed to settle and filtered through Whatman No. 40 ashless filter papers. The filtrate was then centrifuged at $3000 \mathrm{rpm}$ and the content of the flasks analyzed using Flame-AtomicAbsorption Spectrometer (FAAS; 300A) at a wavelength of $359 \mathrm{~nm}$.

\section{Determination of the effect of temperature:}

$1.0 \mathrm{~g}$ each of PWB and CWB of $106 \mu \mathrm{m}$ mesh particle size were weighed and placed in five different plastic bottles with cover. $50 \mathrm{ml}$ of Chromium (VI) solution of concentration $100 \mathrm{mg} / \mathrm{l}$ was prepared from the stock solution and added to PWB and CWB in the plastic bottles with temperature labels of $30,40,50,60$ and $70^{\circ} \mathrm{C}$ respectively. The mixtures were adjusted to $\mathrm{pH}$ of 5.0. The plastic bottles containing the mixtures were then heated to the appropriate temperature. At the end of the heating period, the mixtures were filtered through Whatman No. 40 ashless filter papers. The filtrate was then centrifuged at $3000 \mathrm{rpm}$ and the content of the flasks analyzed using Flame-Atomic-Absorption Spectrometer (FAAS; 300A) at a wavelength of 359 nm.

\section{Analysis of Chromium (VI) Content}

The Chromium (VI) ion content in all the experiments was determined by a Buck Scientific Flame-Atomic-Absorption Spectrometer (FAAS; 300A) at a wavelength of $359 \mathrm{~nm}$. Analytical grade standards were used to calibrate the instrument, which was checked periodically throughout the analysis for instrument's response.

\section{Calculation of metal ion uptake by biomass}

The amount of chromium (VI) removed by the FPWB during the batch investigations was determined by means of mass - balance expression (Eqn 1):

$$
\mathrm{q}_{\mathrm{e}}=\frac{\mathrm{V}\left(\mathrm{C}_{\mathrm{i}}-\mathrm{C}_{\mathrm{e}}\right)}{\mathrm{W} 1000}
$$

Here $q_{e}$ is the metal concentration on the biomaterial $(\mathrm{mg} / \mathrm{g}), C_{i}$ is the initial metal concentration in solution $(\mathrm{mg} / \mathrm{l}), C_{e}$ is the metal concentration in solution $\left(\mathrm{mg} \mathrm{l}^{-1}\right)$ at equilibrium, $v$ is the volume (in $\mathrm{mL}$ ) of initial metal solution used, and $w$ represents the mass (in g) of biomass used. The batch experiments were performed in triplicates, and the means were taken for each set of values.

\section{Kinetic Treatment of experimental data}

The time dependent data of this study was analyzed using the pseudo - first and pseudo second order kinetic models. The linearized form of the pseudo-first order equation is generally expressed as (Eqn 2): 


$$
\log \left(q_{e}-q_{t}\right)=\log \left(q_{e}\right)-\frac{k_{1}}{2.303} t
$$

Where $\mathrm{q}_{\mathrm{e}}$ and $\mathrm{q}_{\mathrm{t}}$ are the sorption capacity at equilibrium and at time, $\mathrm{t}$ respectively $(\mathrm{mg} / \mathrm{g}), \mathrm{k}_{1}$ is the rate constant $\left(\mathrm{g} /(\mathrm{mg} / \mathrm{min})\right.$ of pseudo-first order kinetics. The plot of $\log \left(\mathrm{q}_{\mathrm{e}}-\mathrm{q}_{\mathrm{t}}\right)$ versus $\mathrm{t}$, after linearization give a relationship from which $\mathrm{k}_{1}$ and $\mathrm{q}_{\mathrm{e}}$ can be calculated from the slope and intercept respectively.

The linear form of the kinetic rate-expression model for a pseudo-second order reaction developed by Ho et al. ${ }^{15}$, was also applied to the time dependent experimental data of this study and is given in equation 3 :

$$
\frac{t}{q_{t}}=\frac{1}{h_{0}}+\left(\frac{1}{q_{t}}\right) t
$$

In this equation, $\mathrm{q}_{\mathrm{t}}$ is the amount of metal ions on the FPWB surface $(\mathrm{mg} / \mathrm{g})$ at time $\mathrm{t}, \mathrm{q}_{\mathrm{e}}$ is the amount $(\mathrm{mg} / \mathrm{g})$ of metal ions adsorbed at equilibrium, and $\mathrm{h}_{\mathrm{o}}$ is the initial sorption rate $(\mathrm{mg} / \mathrm{min})$. The initial sorption rate, $h_{0}$, is given in in equation 4 :

$$
\mathrm{h}_{\mathrm{o}}=K_{2} q_{e}^{2}
$$

Where $K_{2}$ is the pseudo-second order rate constant $\left(\mathrm{g} /(\mathrm{mg} / \mathrm{min})\right.$. The parameters $h_{\mathrm{o}}$ and $\mathrm{K}_{2}$ are determined experimentally from the slope and intercept of a plot of $t / \mathrm{q}_{\mathrm{t}}$ against $\mathrm{t}$.

\section{Thermodynamic treatment of experimental data}

Experimental data of the effect of temperature on the sorption process was analyzed using different equations, which made it possible to determine some thermodynamic parameters such as free energy change $\left(\Delta \mathrm{G}^{0}\right)$, enthalpy change $\left(\Delta \mathrm{H}^{0}\right)$ and entropy change $\left(\Delta \mathrm{S}^{0}\right)$. The adsorption equilibrium constant $\mathrm{K}_{0}$ was estimated from the expression in equation 5:

$$
\mathrm{K}_{0}=\frac{C_{e}}{C_{0}}
$$

Where $\mathrm{Ce}$ is the concentration of solution at equilibrium $(\mathrm{mg} / \mathrm{l})$ and $\mathrm{Co}$ is the initial concentration of solution $(\mathrm{mg} / \mathrm{l})$.

The thermodynamic parameters were obtained from equations 6 and 7 as given below.

$$
\begin{aligned}
& \Delta \mathrm{G}^{0}=-\mathrm{RT} \operatorname{InK}_{0} \\
& \mathrm{InK}_{0}=\frac{\Delta S^{0}}{R}-\frac{\Delta H^{0}}{R T}
\end{aligned}
$$

Where $\Delta \mathrm{G}^{0}$ free energy change; $\Delta \mathrm{H}^{0}$ enthalpy change and $\Delta \mathrm{S}^{0}$ entropy change, $\mathrm{R}$ is universal gas constant $(8.314 \mathrm{~J} / \mathrm{mol}), \mathrm{T}$ is temperature in Kelvin, $\mathrm{K}_{\mathrm{o}}$ is the thermodynamic equilibrium constant.

\section{Results}

Kinetic Treatment of the adsorption process 
A plot of $\log \left(\mathrm{q}_{\mathrm{e}}-\mathrm{q}_{\mathrm{t}}\right)$ versus $\mathrm{t}$, of the linearized form of the pseudo-first order model as expressed in equation 2 was taken and shown in figure 1. The pseudo-first order rate constant, $\mathrm{K}_{1}$ and the equilibrium sorption capacity, $\mathrm{q}_{\mathrm{e}}$, were obtained from the slope and intercept of figure 1 and with the coefficients of determination, $\mathrm{R}^{2}$ are presented in Table 1 .

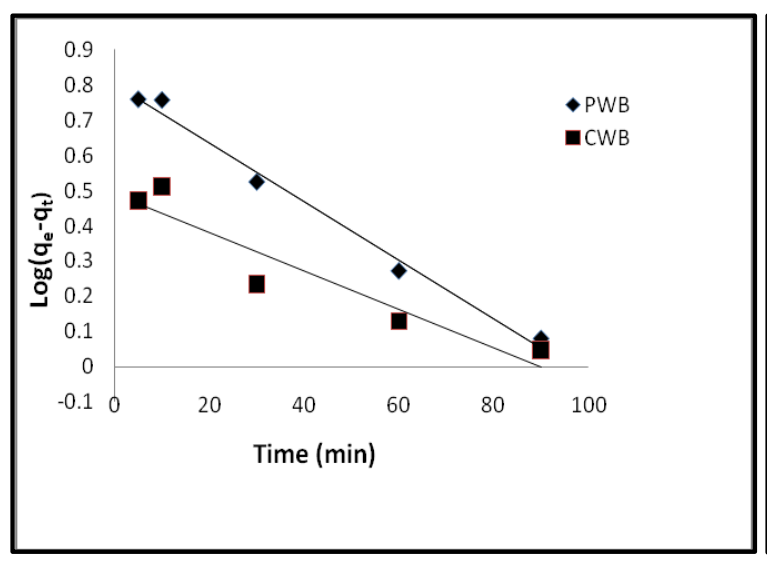

Figure 1: Plot of pseudo-first order rate model for the removal of $\mathrm{Cr}(\mathrm{VI})$ ion from aqueous solution by $P W B$ and $C W B$

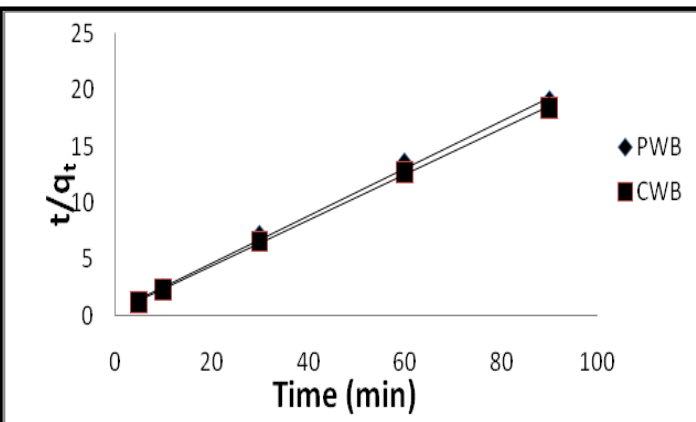

Figure 2: Plot of pseudo-second order rate model for the removal of $\mathrm{Cr}$ (VI) ion from aqueous solution by $P W B$ and $C W B$

The pseudo-second order rate equation was also tested using the time dependent data obtained in this study by plotting t/qt versus $t$ as in equation 3. The plot is shown in Fig. 2. The plot as shown in figure 2 was linear, and the initial sorption rate $h_{o}$, the equilibrium sorption capacity, $\mathrm{q}_{\mathrm{e}}$, the pseudo-second order rate constant, $\mathrm{K}_{2}$ were obtained from the slope and intercept of Fig. 2 and with the coefficient of determination, $R^{2}$ are given in Table 2.

Table 1: Pseudo-first-order rate constant parameters for Cr (VI) ion removal from solution by $P W B$ and $C W B$

\begin{tabular}{|l|l|l|l|}
\hline Adsorbent & $\mathrm{K}_{1}$ (mg/g. min.) & $\mathrm{q}_{\mathrm{e}}(\mathrm{mg} / \mathrm{g})$ & $\mathrm{R}^{2}$ \\
\hline PWB & 0.01267 & 0.309 & 0.894 \\
\hline CWB & 0.01933 & 0.0949 & 0.9892 \\
\hline
\end{tabular}

\section{Thermodynamic treatment of the sorption process}

The thermodynamics of the sorption of $\mathrm{Cr}$ (VI) ion from aqueous solution by $\mathrm{PWB}$ and CWB was evaluated using the temperature dependent experiments of this study. The thermodynamic studies made it possible to determine parameters such as the free energy change, $\Delta \mathrm{G}^{0}$, enthalpy change, $\Delta \mathrm{H}^{0}$ and entropy change, $\Delta \mathrm{S}^{0}$. The thermodynamic parameters were calculated from equations 6 and 7. Using equation 6 , the apparent free energy change, $\Delta \mathrm{G}^{0}$ for the range of temperatures investigated was calculated and is presented in Table 3 . 
Table 2: Pseudo-second-order rate constant parameters and regression coefficients for Cr (VI) ion removal from solution by $P W B$ and $C W B$

\begin{tabular}{|l|l|l|l|l|}
\hline Adsorbent & $\mathrm{q}_{\mathrm{e}}(\mathrm{mg} / \mathrm{g})$ & $\mathrm{K}_{2}(\mathrm{mg} / \mathrm{g} . \mathrm{min})$ & ho $(\mathrm{mg} / \mathrm{g} . \mathrm{min})$ & $\mathrm{R}^{2}$ \\
\hline PWB & 4.76 & 0.093 & 2.11 & 0.9975 \\
\hline CWB & 4.93 & 0.133 & 3.23 & 0.9994 \\
\hline
\end{tabular}

From equation 7 , a plot of $\ln K_{\mathrm{o}}$ versus reciprocal of temperature $(1 / \mathrm{T})$ was taken and is given in Fig. 3. The plot as presented in figure 3 was linear, and the values of $\Delta H^{0}$ and $\Delta S^{0}$ were calculated from the slopes and intercepts of these plots. The value of $\Delta \mathrm{G}^{0}$ was calculated from equation 6 . The thermodynamic parameters; free energy change $\Delta \mathrm{G}^{0}$, enthalpy change, $\Delta \mathrm{H}^{0}$, entropy change, $\Delta \mathrm{S}^{0}$ and coefficients of determination $\left(\mathrm{R}^{2}\right)$ for PWB and CWB are presented in Table 4.

\section{Discussion}

Kinetic Treatment of the adsorption process

sorption kinetics describe the solute uptake rate at the solid-solution interface, and it is important for designing appropriate treatment plants to predict the rate at which any pollutant is removed from aqueous solution. The biomass is a complex material containing mainly organic residues such as lignin, cellulose, and is made of several polar functional groups. These groups are involved in chemical bonding and are responsible for the cation exchange capacity of the biomass ${ }^{16}$.

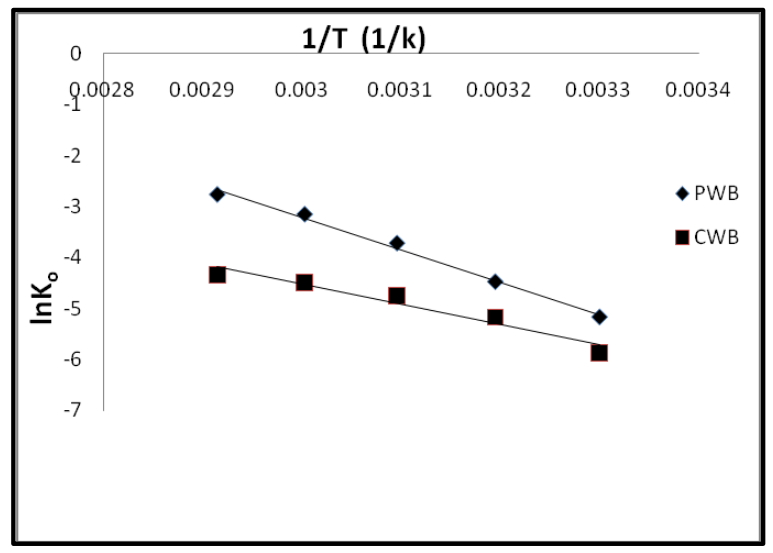

Figure 3: Plots of $\ln K_{o} V s$ 1/T for Cr(VI) ion removal from aqueous solution by $P W B$ and CWB

The data as presented in Table 1 shows that CWB has higher sorption rate than PWB. The pseudo-first order rate equation was suitable for describing the time dependent data of this study for CWB $\left(\mathrm{R}^{2}=0.9892\right)$ but did not show a good fit for PWB $\left(\mathrm{R}^{2}=0.8940\right)$.

Results in Table 2 show that the CWB has higher initial sorption rate $\left(\mathrm{h}_{\mathrm{o}}=3.232 \mathrm{mg} / \mathrm{g} \mathrm{min}\right)$ than the PWB $\left(h_{o}=2.111 \mathrm{mg} / \mathrm{g} \min \right)$. This shows that carbonization of biomass enhanced the 
sorption potential of the biomass towards $\mathrm{Cr}$ (VI) ions probably by providing larger surface area. The data on the pseudo second order rate model further shows that high correlation coefficient values $\left(R^{2}=0.9975\right.$ and 0.9994$)$ were obtained for the PWB and CWB respectively.

Table 3: Gibbs free energy change for the sorption of $\mathrm{Cr}$ (VI) from solution at different temperatures by $P W B$ and $C W B$

\begin{tabular}{|l|l|l|}
\hline \multirow{2}{*}{ Temperature $\left({ }^{\circ} \mathrm{C}\right)$} & \multicolumn{2}{|c|}{$\Delta \mathrm{G}^{0}\left(\mathrm{KJmol}^{-1} \mathrm{~K}^{-1}\right)$} \\
\cline { 2 - 3 } & $\mathrm{PWB}$ & $\mathrm{CWB}$ \\
\hline 30 & -13.017 & -14.807 \\
40 & -11.643 & -13.447 \\
50 & -9.983 & -12.739 \\
60 & -8.718 & -12.038 \\
70 & -7.875 & -122.341 \\
\hline
\end{tabular}

The high correlation coefficient values show that the pseudo second order rate model was suitable for describing the experimental data obtained in this study. Both the equilibrium sorption capacities, $\mathrm{q}_{\mathrm{e}}(4.764 \mathrm{mg} / \mathrm{g}$ and $4.93 \mathrm{mg} / \mathrm{g})$ and correlation coefficients, $\mathrm{R}^{2}(0.9975$ and 0.9994) for PWB and CWB respectively for pseudo second order model are found to be higher than for pseudo first order model, $\mathrm{q}_{\mathrm{e}}(0.309 \mathrm{mg} / \mathrm{g}$ and $0.0949 \mathrm{mg} / \mathrm{g})$ and $\mathrm{R}^{2}(0.894$ and 0.9892$)$ respectively. Thus, the sorption of $\mathrm{Cr}$ (VI) from aqueous solution was best described by the pseudo second order equation.

Table 4: Thermodynamic parameters for the removal of $C r(V I)$ ions from solution by $P W B$ and $C W B$

\begin{tabular}{|l|l|l|l|l|}
\hline Adsorbent & $\Delta \mathrm{H}^{0}\left(\mathrm{Jmol}^{-1}\right)$ & $\Delta \mathrm{S}^{0}\left(\mathrm{Jmol}^{-1} \mathrm{~K}^{-1}\right)$ & $\Delta \mathrm{G}^{0}\left(\mathrm{KJmol}^{-1}\right)$ & $\mathrm{R}^{2}$ \\
\hline PWB & -31.39 & 56.44 & -13.017 & 0.9188 \\
\hline CWB & -51.085 & 126.35 & -14.807 & 0.9839 \\
\hline
\end{tabular}

The values of $\Delta \mathrm{G}^{0}$ in table 3 are found to be negative at all temperatures investigated, which shows that the sorption of $\mathrm{Cr}$ (VI) by the PWB and CWB is feasible and the sorption process is spontaneous in nature. It was also observed that $\Delta \mathrm{G}^{0}$ values are less than $-20 \mathrm{KJmol}^{-1}$, indicating physisorption. It is of note that values of $\Delta \mathrm{G}^{0}$ up to $-20 \mathrm{KJmol}^{-1}$ are consistent with electrostatic interaction between sorption sites and the metal ions (physisorption) while $\Delta \mathrm{G}^{0}$ values more than $-40 \mathrm{KJmol}^{-1}$ involve charge sharing or transfer from the biomass surface (chemisorption).

The negative values of $\Delta \mathrm{H}^{0}$ (table 4) shows the exothermic nature of the sorption process, therefore lower solution temperature favours the sorption process. The positive values of $\Delta \mathrm{S}^{0}$ indicate that the adsorbed metal ions are not too restricted to the biomass, thus confirming a physical sorption process, which is in agreement with the relatively low values of $\Delta \mathrm{G}^{0}$. Similar results were obtained when Rhizophora Mangle waste was used as adsorbent for metal ions removal from aqueous solution [17]. 


\section{Conclusion}

The results obtained from this study show that PWB and CWB have very high removal capacity for chromium (VI) from aqueous solution over a range of reaction conditions. The kinetic data shows that both the pseudo-first-order and pseudo-second-order models were suitable for describing the time dependent data of this study. The thermodynamic treatment of the sorption process shows a negative value for heat of adsorption $\left(\Delta \mathrm{H}^{0}\right)$ which indicates that the sorption process is exothermic. And the negative values of free energy change $\left(\Delta \mathrm{G}^{0}\right)$ indicate that the sorption of $\mathrm{Cr}$ (VI) from aqueous solution by PWB and CWB is feasible and spontaneous in nature. Thus, fluted pumpkin waste biomass (Telfairia occidentalis Hook F) is a potential sorbent for the treatment of industrial effluents containing chromium (VI) contaminant.

\section{References}

1. B. J. Alloway and A. K. Ayres : Chemical Principles of Environmental Pollution (2 ${ }^{\text {nd }}$ edn.), 1997, p.214.

2. D. J. Porter, L. W. Raymond and G. D. Anastasio, J. Arch. Fam. Medi. 1999, 8, 386.

3. A. J. Mearns, Toxicity studies of chromium. Annual report Southern California Coastal Water Research Project, 1974.

4. F. Strreth, Scavengers, 1978, 8, 7.

5. N. K. Lazaridis, K. A. Matis and M. Webb, Chemosphere, 2001, 42, 373.

6. N. K. Hamadi, X. D. Chen, M. M. Farid and M. G. Q. Lu, Chem. Eng. J., 2001, 84, 95.

7. N. K. Lazaridis and D. D. Asouhidou, Wat. Res. 2003, 37, 2875.

8. I. Han, M. A. Schlautman and B. Batchelor, Wat. Environ. Res. 2001, 72, 29.

9. M. Horsfall jnr., A. Abia and A.I. Spiff, Afric. J. Biotechnol. 2003, 2, 969.

10. M. Horsfall jnr. and A. I. Spiff, Afric. J. Biotechnol. 2005, 4, 191.

11. T. Tarawou, M. Horsfall jnr. and J. L. Vicente, Chem. \& Biodiv. 2007, 4, 2236.

12. U. C. Gbosh, M. Dasgupta, S. Debnath, and S. C. Bhat, Wat. Air Soil pollut. 2003,143, 245.

13. S. Rengaraj, K. H. Yeon and S. H. Moon, J. Hazard Mater. 2001, B87, 273.

14. M. Horsfall jnr. and A. I. Spiff, Chem. \& Biodiv. 2005b, 2, 373.

15. Y. S. Ho, W. D. A. John and C. F. Forster, Wat. Res. 1995, 29, 1327.

16. Y. S. Ho and G. McKay, J. Environ. Sci. Health, 1999, A34, 1179.

17. N. Ayawei, M. Horsfall jnr and A. I. Spiff, Eur. J. Sci. Res., 2005, 9, 6. 